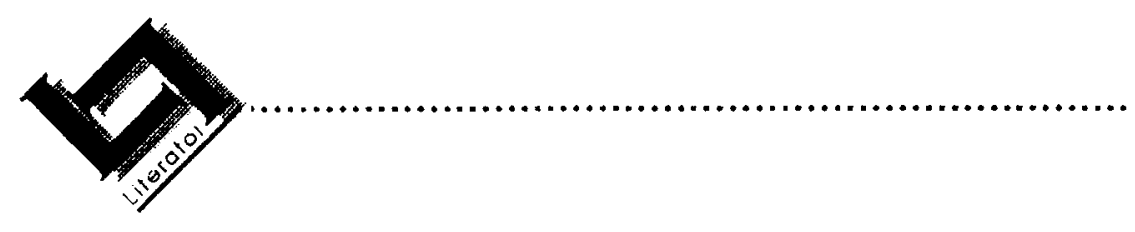

\title{
Die romanse en romantiese karakters
}

\section{Chanette Paul}

\section{Ter inleiding}

André Jute sê ter inleiding van sy boek Writing a Thriller:

In this book I intend to provide you with $0.9 \%$ of the fabric that makes up a published writer; that is the most help anyone can realistically offer the aspiring writer. The rest of the whole writer is made up of $0,1 \%$ communicative ability, often miscalled 'talent', and the remaining $99,0 \%$ is the balance of genius and perspiration, though I shall call it perserverance because that more aptly describes the writer's condition.

Die slegte nuus is dus dat geen "How to ..."-boek of -artikel van 'n mens 'n skrywer kan maak nie. Niemand kan 'n ander leer skryf nie, al wil sy ook hoe graag.

Skryf is egter ' $n$ ambag soos enige ander. Daar is seker mense wat van nature met alles toebedeel is om 'n skrywer te wees - mense wat op 'n dag gaan sit, 'n wenner skryf en hope geld daaruit kan maak. Ek neem aan dis moontlik, maar vir die res van ons gewone sterflinge is die saak egter so ' $n$ fraksie moeiliker. As jy nie soos 'n loodgieter of 'n timmerman die regte toerusting het nie en nie die nodige tegnieke onder die knie het nie, sal dit maar bars gaan - iets wat ek duidelik sien uit my keurwerk.

Die toerusting van die skrywer is die volgende:

- Die taal en die vermoë om dit kreatief in te span.

- Die sintuie en die gebruik daarvan om die skrywer te dien in haar skryfwerk.

- 'n Paar tegnieke of fyner kunsies van die bedryf wat die skrywer aanleer deur middel van waarneming, bestudering asook - en meestal - probeer en fouteer.

- 'n Onstuitbare wil, uithouvermoë en vasberadenheid. 
Aan drie van hierdie sake kan mens met 'n kursus van watter aard ook al nie veel doen nie.

lemand kan jou leer om taal korrek en beter te gebruik, maar die vermoë om taal kreatief te gebruik is deel van die talent.

Dieselfde geld vir die sintuie. Niemand leer 'n mens waarna om te kyk of te luister, wat en hoe om te proe of te voel of te ruik om dit in jou skryfwerk te gebruik nie. Wat ek wel kan sê, is gebruik jou eie sintuie en veral dié van jou karakters waarmee jy werk.

Ook kan niemand iets aan jou deursettingsvermoë doen nie. Dis 'n stryd, en 'n eensame een, wat elkeen ongelukkig op sy eie moet volstry.

Wat ek wel met die aspirantskrywer kan deel, is dit wat ek deur die jare geleer het met sowel my skryfwerk as met my keurwerk, maar ook met my studie en leeswerk. Wat ek in hierdie artikel op skrif stel, is egter hoofsaaklik vanuit die perspektief van 'n skrywer, want dis wat ek, binne my vermoë, die beste doen, naamlik skryf.

Behalwe dat ek niemand dus kan leer skryf nie, moet ek ook die volgende bieg:

- Mens kan nie 'n boek, selfs 'n romanse waarop daar so neergesien word, volgens nommers skryf soos jy kan prentjies verf volgens nommers nie. Daar is egter riglyne wat kan werk as dit die muse behaag. 'n paar basiese stukke gereedskap wat jy kan gebruik of verwerp soos die muse jóú lei.

- Selfs al doen jy alles reg en presies soos wat 'n gepubliseerde skrywer voorstel, is daar geen waarborg vir sukses nie. Jy kan moontlik die geluk tref en 'n boek skryf wat 'n wegholsukses is, maar dis ook moontlik dat een of ander onheilige keurder jou manuskrip gaan terugstuur en sê skryf oor. Dis alles deel van die proses en die waansin van skryf.

- ' $n$ Artikel soos hierdie is nie bedoel om jou in 'n korset in te dwing nie. Wees krities en gebruik wat vir jou werk.

- Geen enkele skrywer het al die antwoorde nie. Dinge wat vir my werk, sal nie noodwendig vir jou werk nie en ander skrywers lag moontlik as hulle hoor hoe ek te werk gaan. Ek weet Deon Meyer sal tot in sy motorfietsstewels sidder as hy hoor ek werk sonder 'n gedetailleerde raamwerk, maar wat vir hom werk, werk nie vir my nie. Jeanette Ferreira doen haar bewonderenswaardige navorsing vooraf. Ek weer, leer algaande en gaan na die tyd terug wanneer ek nie seker is oor 
my feite nie. Ek skryf nie eers 'n volledige draft soos die grootste deel van die kursusaanbieders in die vrye wêreld voorstel nie. Ek lees elke dag wat ek die vorige dag geskryf het en 'n ent terug, verander en pas aan voordat ek verder skryf. Ek bevind myself gelukkig in goeie geselskap, want Marita van der Vyver pleit klaarblyklik ook skuldig hieraan. Buitendien, die voordeel is dat jou uiteindelike redigering minimaal is.

In mý geval werk dit, maar elkeen moet maar vir hom-/haarself uitmaak hoe relevant hierdie idees vir sy/haar eie skryfwerk is.

- Laastens moet ek bieg dat die hele idee om te skryf, laat staan ander te probeer leer om te skryf, 'n soort waansin is. Maar wat 'n wonderlike waansin!

Ek is beter bekend vir my liefdesverhale as vir enige ander skryfwerk en daarom wil ek verder op die liefdesverhaal konsentreer.

\section{Persepsies}

Daar is ' $n$ paar vrae en opmerkings wat gereeld en minder gereeld na skrywers, en spesifiek skrywers van liefdesverhale, se kant toe kom. Een hiervan is: "Ek sou ook baie graag wou skryf, as ek net die tyd gehad het".

Hierdie versugting kom van min of meer elke derde persoon wat hoor jy skryf. Soos Donna Baker vra: "Kan jy jou indink dat iemand sê: 'Ek sou graag 'n dokter/prokureur wou gewees het as ek net die tyd gehad het'?"

Een vraag kom van 'n baie spesifieke groep. Hulle vra dit gewoonlik kopskuddend en met ' $n$ frons. Hulle weet gewoonlik van die graadsertifikaatjies wat ewe sedig op 'n ry in jou studeerkamer hang. Hulle vra asof hulle iets onwelriekend ruik: "Het jy al ooit daaraan gedink om regte boeke te skryf?" Sou hulle aan 'n dokter vra of hy al daaraan gedink het om 'n regte dokter te word of wanneer begin hy regte medisyne voorskryf?

Hulle elitistiese eweknieë, dikwels net nie heeltemal so geleerd nie, skud weer net kop. "Hygromans? Gits, nee, ek lees nie sulke ligte goed nie". En in dieselfde asem "Is daar mense wat werklik dié goed lees?" Dis dikwels dieselfde mense wat ontken dat hulle sepies kyk, maar presies weet wie Nenna, die Vorsters en die Forresters is.

Die kersie op die koek is miskien 'n beroepsvrou van veertig plus wat tot dusver elkeen van my boeke verslind het, en van wie ek moes hoor: "Ek 
trek die hygromans met bruinpapier oor sodat mense nie sien wat ek lees nie".

\section{Wat is 'n liefdesverhaal en waaroor gaan dit in die liefdesverhaal?}

Ek wil die term hygroman voorlopig tersyde stel. Dit is myns insiens onnatuurlik om 'n onderskeid te maak tussen 'n "gewone" liefdesverhaal en 'n hygroman. Daar is heelwat "gewone" liefdesverhale met warmer liefdestonele as in hygromans en die omgekeerde is ook waar. Ek verwys liewer na die liefdesverhaal oor die algemeen.

Wat is 'n liefdesverhaal en waaroor gaan dit in die liefdesverhaal? Die voor die hand liggende antwoord is dat dit oor die liefde gaan. Hierdie antwoord skiet egter te kort. Waaroor gaan dit uiteindelik in War and Peace, in Tristan und Isolde, in Like Water for Chocolate, The English Patient, Isabel Allende se boeke, Anna Karenina en dies meer? Ook tog uiteindelik die liefde, maar hierdie romans val beswaarlik in die kategorie van die liefdesverhaal soos ons dit hier verstaan.

As ons dan moet kategoriseer, sal ek eerder van drie terme gebruik maak om 'n onderskeid te tref tussen groepe boeke wat handel oor die liefde. Nóg die onderskeid tussen die groepe, nóg die benaminge is noodwendig akademies verantwoord, maar dis 'n basiese onderskeid wat gemaak word deur heelwat mense wat oor die liefdesverhaal skryf. Ek gee dus nie voor dat hierdie onderskeid die allerantwoord is of dat die kategorieë nie soms oorvleuel nie.

Ek wil die onderskeid tref tussen die romanse (romance), die liefdesroman (romantic novel) en die literêre roman wat liefde as tema het. Die derde kategorie gaan ek nie eers probeer omskryf nie, maar daaronder val, myns insiens, boeke soos Anna Karenina. Dis nie 'n kategorie wat van toepassing is vir hierdie artikel nie, want ek het dit hier oor ontspanningslektuur, verstrooiingsliteratuur, ontvlugtingslektuur of wat 'n mens dit ook al wil noem.

Dit laat ons dus met die romanse en die liefdesroman.

\section{Die verskil tussen 'n romanse en 'n liefdesroman}

\section{- Die romanse (romance - Mills \& Boon-tipe liefdesverhale)}

'n Romanse is bloot dit - die storie van 'n liefdesverhouding wat tussen 'n man en 'n vrou ontwikkel. Die ontwikkeling begin van die oomblik dat daardie chemiese reaksie vonk vat en duur tot en met die die kulminering van hierdie liefde - sy dit 'n huweliksaansoek, hul eerste keer in 
die kooi, die troue, die aankoms van hul eerste baba of waarheen die storie ook al lei.

Onder die term romanse, val - vir my in elk geval - die hygroman (as die term moet) van Perskor/MML, die boekklubroman van J.P. van der Walt - nou Lapa - en die grootste gros van die boeke wat deur Tafelberg en Human \& Rousseau uitgegee word onder die benaming liefdesverhale.

Uiteraard is daar sake rondom die liefdesverhouding wat in die verhaal ontgin word. Dit kan enigiets behels, van onderwaterekologie tot klerefabrieke, van fotografie en modesessies tot wildbewaring, maar uiteindelik is die belangrikste aspek die groeiende verhouding en hoe die held en heldin al die struikelblokke om by mekaar uit te kom, oorkom.

Waarom romanses soveel kritiek ontlok, is vir my duister. Dit is ' $n$ genre met groot aanhang by sy teikenleser. En net soos ' $n$ mens ' $n$ goeie of ' $n$ swak speurverhaal of literêre werk kry, kan jy 'n goeie of ' $n$ swak liefdesverhaal kry. Dit gaan dus vir my nie daarom in watter genre ek skryf nie, maar of ek die genre onder die knie het en goed skryf binne daardie genre.

Die belangrikste bestanddele van die romanse is hoegenaamd nie seksdade op elke derde bladsy nie, maar wel 'n heldin met wie die leser kan identifiseer en emosies wat die leser by die lees van die verhaal roer. Dit is die emosies wat die heldin deurgaan, maar deur die leser ervaar word, wat die romanse sy verslawende element besorg. Sonder die heldin en haar emosies is 'n verhaal nie 'n romanse nie. Die skrywer van romanses se taak is tot ' $n$ mate bloot om die emosies van daardie duiselingwekkende gevoelens wat 'n mens ondervind wanneer jy werklik halsoorkop verlief raak, binne storieverband.

Wie kan immers vergeet hoe dit gevoel het? Daardie angstige vreugde wanneer die foon lui, die son wat helderder skyn wanneer hy jou raakgesien het en die wolke wat donkerder as ooit voorheen dreig as jy nie van hom gehoor het nie? Die gevoel dat jy oor die aarde sweef eerder as loop, die bewing in jou hande as die objek van jou bewondering binne trefafstand kom?

Ek dink nie ons vergeet ooit daardie gevoelens of die impak wat dit op ons gehad het nie. In die romanse lei ons die leser om daardie gevoelens weer by hernuwing te ervaar. Daarom is ' $n$ ongelukkige einde in die romanse ' $n$ absolute taboe.

Die romanse beskryf die proses van die liefdesverhouding en sluit af met die verwagting dat die held en heldin 'n goeie kans staan om min of meer 
gelukkig getroud/by mekaar te wees. As dit die groot sonde is wat voor die skrywer van die romanse se deur gelê word, sondig ek graag voort.

Maar net omdat die einde gelukkig moet wees, beteken nie dat dit sommer maklik gaan in die romanse nie - inteendeel. Die les van die feëverhaal is die basiese les van alle liefdesverhale, insluitende die romanse, naamlik: liefde wat nie getoets is nie, is nie ware liefde nie. Liefde moet deur swaarkry beproef word voordat dit werklik kan seëvier. Sewe sakke sout dus, maar met die beloning - 'n gelukkige einde.

Ek het vyf boeke in hierdie genre gepubliseer en die skryf daarvan geniet, maar niemand moet vir my kom sê dit is maklik net omdat daar binne sekere parameters geskryf word nie. Parameters of nie parameters nie, 'n romanse is niks makliker om te skryf as 'n liefdesroman nie. Wat die skryftyd betref, gaan dit soms vinniger, maar dan bloot omdat dit net ongeveer 40000 woorde verg in vergelyking met die historiese liefdesroman van ongeveer 80000 woorde en 'n liefdesroman soos Wip van die droomvanger van 130000 woorde.

- Die liefdesroman (romantic novel - Danielle Steele, Janet Dailey, Judith Krantz, Madge Swindells ens.)

Die opvallendste kenmerk van die tipiese liefdesroman is dat dit langer is - heelwat langer. Oorsese uitgewers vereis ongeveer 100000 woorde plus. In Suid-Afrika glo ek nie is daar spesifieke standaarde nie. Perskor het op 'n stadium blockbuster-tipe boeke uitgegee en die woordetal op 120000 vasgestel, maar tans konsentreer hulle alleenlik op romanses. Boeke wat onder die blockbuster-konsep uitgegee is, was onder meer Babette van Jeanette Ferreira, Adrenalien en Die plesierengel van Leon van Nierop, Amulet van Elize Parker en my Wip van die droomvanger. Hierdie boeke val almal tot ' $n$ mindere of meerdere mate in die liefdesromangenre.

Omdat die liefdesroman so baie verskil van die romanse, is dit begryplik dat skrywers vies word as enige boek waarin dit om die liefde gaan, as hygromans afgeskryf word. Ek het geweldig baie simpatie met Jeanette Ferreira byvoorbeeld, wie se Babette dikwels ook as hygroman geklassifiseer word deur die elitiste - wat nie weet wat die verskil is tussen die romanse en die liefdesroman nie en klaarblyklik nie eers besef dat daar wel ' $n$ verskil bestaan nie.

Die liefdesroman strek wyer as die romanse, dit beweeg ook nader aan die realiteit. In die liefdesroman kan die minder idilliese kant van die lewe betrek word, die onregverdigheid van die lewe, menslike wreedheid, die struikelblokke wat oor die mens se pad kom en dies meer. Daar loop 
egter steeds 'n goue draad van hoop en optimisme deur die verhaal. Al word die hoof- en ander karakters blootgestel en soms uitgelewer aan nare werklikhede, werk alles uiteindelik tog reg uit vir die held en die heldin.

Die einde van die liefdesroman hoef nie idillies te wees nie, maar die verhaal moet op 'n positiewe noot eindig. Jou leser vergewe jou nie altyd vir aweregse eindes nie, soos sommige lesers my maar nie kan vergewe vir Wip ... se einde nie, maar in die liefdesroman gaan dit oor 'n positiewe, min of meer realistiese einde eerder as 'n sprokieseinde.

Waar die romanse dus die donkerder kant van die lewe grootliks ignoreer (let wel, nie ontken nie), word dit in die liefdesromans wel betrek. Baie dinge wat in die romanse ontgin word, gebeur wel in die werklike lewe, maar baie dinge wat in die werklike lewe gebeur, word nie in die romanse weergegee nie. In die liefdesroman egter wel.

Liefdesromans is warm, emosionele stories wat jou met 'n gevoel van behaaglikheid laat, maar stories wat die werklikheid betrek.

Dit dan die verskil in hooftrekke tussen die romanse en die liefdesroman. Vir die doeleindes van die artikel konsentreer ek verder hoofsaaklik op die romanse.

\section{Die binnegoed en werkinge van 'n romanse}

Daar is 'n paar elemente waarsonder 'n storie, enige storie, net nie kan nie. Hierdie onontbeerlike elemente of bestanddele van 'n storie is karakters, tyd en ruimte, gebeure en handelinge, die tema en plot. En binne hierdie elemente is daar dinge aan die werk soos die verteller en die fokalisators, showing en telling. Ek sou baie graag op die verteller en die fokalisators ingegaan het, aangesien dit vir my baie belangrike aspekte is wat 'n verhaal kan maak of breek. In my keurwerk sien ek dat dit 'n groot probleem is vir onervare skrywers. Dis egter moeilik om dit te doen sonder spesifieke voorbeelde en ek glo nie dit sal eties korrek wees om voorbeelde uit my keurwerk aan te haal nie.

Ek het egter ook agtergekom dat daar ' $n$ ander element is wat nogal verwaarloos word deur die onervare skrywer; een van die belangrikste elemente van 'n verhaal, naamlik die karakters.

\subsection{Karakters}

Veral in die romanse is die karakters die spil waarom alles draai. Sonder karakters kan daar geen romanse wees nie en dus geen storie nie. 
Die potensiaal vir 'n goeie liefdesverhaal lê dan ook in die karakters opgesluit, eerder as in die gebeure. Die liefdesplot is uiteindelik 'n karakterplot. Die suksesvolle liefdesverhaal werk as gevolg van daardie elektriese vonk tussen die hoofkarakters. 'n Plot kan allerhande interessante kinkels en draaie hê, maar in die liefdesverhaal gaan dit weinig beteken as die hoofkarakters nie daardie spesiale stomende iets tussen hulle ervaar nie. En daarmee bedoel ek nie dat hulle noodwendig in die kooi spring nie; inteendeel, dis hoofsaaklik 'n onderliggende emosie wat telkens dreig om oor te kook. Dit geld vir alle liefdesverhale, maar in die besonder vir die romanse.

Benewens die hoofkarakters, die held en die heldin wat op mekaar verlief raak, is daar meestal in die romanse ten minste ' $n$ derde karakter betrokke wat ook 'n prominente rol speel en dan natuurlik ook randkarakters.

\subsection{Die decoy-karakter(s)}

Ek kom later by die held en die heldin en begin by die derde karakter. Hierdie derde karakter (daar kan meer wees, maar hou jou beperkte verhaallengte in gedagte), wat ondergeskik is aan die hoofkarakters, maar nie heeltemal ' $n$ randkarakter is nie, noem ek die decoy. Dit is die man of die vrou wat die leser laat wonder by wie óf die held óf die heldin uiteindelik gaan uitkom. So 'n decoy werk solank dit nie te langdradig word nie. Navorsing dui daarop dat die leser so gou as moontlik wil weet by wie die heldin gaan uitkom - sommer binne die eerste paar bladsye. Onthou, en dis waar baie skrywers hulle misgis, die romanse gaan nie in werklikheid oor wie by wie uitkom nie, maar wel oor hóé hulle by mekaar uitkom. Daarom word romanses ook dikwels van voorspelbaarheid beskuldig. Ek dink nie die beskuldiging het heeltemal meriete nie. Die wie mag voorspelbaar wees, die hoe egter nie. Dit is in die hoe dat die verrassingselement ingebou moet word.

Maar om terug te kom by die decoy, die leser wil nie hoofstuk na hoofstuk lees van die decoy se manewales met die heldin nie. Hy of sy moet daar wees, kompetisie wees en so hier en daar 'n stok tussen die speke druk, maar dit moet duidelik wees dat die held en heldin vir mekaar bedoel is.

\subsection{Randkarakters}

Dit is moeilik om 'n storie net te laat werk met drie karakters. Helde en heldinne het ook ouers, susters, broers, familie en vriende. Hulle het ook vyande, mense wat hulle motors met brandstof volmaak en ken die Griek 
op die hoek by die naam. Hulle het prokureurs, word besoek deur hulle predikant en onthou die onderwysers wat vir hulle skoolgehou het.

Dis egter onmoontlik om al hierdie mense in 'n boek van 40000 woorde te laat figureer. Boonop sou dit onuitstaanbaar vervelig wees om van al hierdie mense te moet kennis neem. Die geheim van randkarakters is om net ' $n$ paar uitgesoektes te gebruik wat werklik 'n bydrae tot die storie maak.

In enige verhaal gebruik 'n mens net die karakters (en dit geld nie net vir karakters nie - ook vir gebeure, handelinge en dies meer) wat 'n impak het op die verloop van die verhaal. As jy 'n storie klaar geskryf het, gaan na jou lys van karakters en vra oor elkeen dié vrae: Wat maak hy in die storie? Dien hy 'n definitiewe doel? Dra hy by tot die verloop van die verhaal? Sal die storie werklik armer wees sonder hom? En let wel, sonder hom, nie sonder die pragtige beskrywing van hom nie.

Randkarakters is nie daar om jou woordtelling vol te maak nie. Elkeen moet funksioneel wees en sy teenwoordigheid moet gemotiveerd en verantwoord wees. Omdat randkarakters reeds min storieruimte kry in vergelyking met die ander drie wat ek genoem het, moet hulle ten minste hul ruimte verdien en soveel moontlik daarvan probeer maak.

\subsection{Die held}

Nou kom ons by die werklik opwindende karakter. Die dae van die tipiese tall, dark and handsome held wat feitlik permanent stilstuipe het onder die vaandel van stille waters diepe grond, is gelukkig verby. So ook die dae van die bombastiese held met Orca onder die een arm en Jaws onder die ander, die een wat die heldin tot oorgawe probeer dwing of haar verdink van allerhande onkuishede en dan op die einde wonderbaarlik besef dat sy eintlik die kuisheid van self is. Helde wat leef en dink en erken hulle is verkeerd, maak dikwels baie interessanter leesmateriaal.

Elkeen van die helde in my romanses het steeds 'n plekkie in my hart. Daar is werklik nie een met wie ek nie ' $n$ diep en innige liefdesverhouding gehad het terwyl ek aan die boek geskryf het nie. Ek glo dit is moontlik omdat nie een van hulle 'n boekhouer of ' $n$ bankbestuurder was nie. Die helde met wie ek kans sien om 'n verhouding aan te gaan, het nie prosaïese beroepe nie: Neil is 'n duik-instrukteur met 'n rits duikskole en ook ' $n$ onderwater-ekoloog. Steph is ook ' $n$ duik-instrukteur en die eienaar van ' $n$ duikoord in Mosambiek. James is 'n fotograaf en die eienaar van 'n hele rits reisagentskappe wêreldwyd. Richard is die grootste beachbum van die lot, maar op 'n luukse seiljag en op die ou 
einde was hy darem ook 'n vennoot in 'n sakeryk. Stas is 'n wildbewaarder en Lukas ' $n$ pediater wat gesmag het na ' $n$ wildsplaas.

Al my helde is wel lank, maar dis bloot omdat ek 'n ding het oor ' $n$ lang man met breë skouers. Ek het onlangs 'n romanse van Madré Meiring gelees waarin die held korter as die decoy-karakter was, maar omdat hy steeds langer as die heldin was en omdat hy so sexy was, het dit gewerk.

Maar terug by die held. Helde hoef nie, behoort selfs nie, mooi mans te wees nie, maar daar moet iets omtrent hulle wees wat aantreklik is. 'n Heldin van formaat sal immers nie na Bill Gates kyk nie, sy bankrekening ten spyt, maar Richard Brandon, wat self nou nie juis iets vir die oog is nie, is weer heeltemal ' $n$ ander saak. Hy het daardie iets wat hom ' $n$ held in 'n verhaal kan maak, al dink ek hy het meer tande as ander mense.

Oor een aspek van die held stem ek en die uitgewer wat al my romanses tot dusver uitgegee het, nie heeltemal saam nie. In teenstelling met haar, glo ek my held mag maar foute hê, solank hy hulle oorkom. Neil het byvoorbeeld in 'n oomblik van swakheid by sy oorlede vrou se suster geslaap en toe vir 'n rukkie lank saam met haar gebly sonder dat hy werklik lief was vir haar. Hy het egter sy dwaalkoers ingesien en dit het van hom 'n meer beskeie mens gemaak. Lukas weer het by Stella aangelê terwyl hy in 'n liefdesverhouding met sy vennoot se dogter was. Ook hy het egter tot sy sinne gekom en 'n beter held aan die anderkant uitgestap. Richard het weer kortstondig en met lang oë gekyk na 'n sexy eks-verloofde van hom. Ek glo dat dit 'n mate van egtheid aan die held verleen, maar ek mag verkeerd wees.

'n Belangrike eienskap van enige held is dat hy seksueel ervare is. Sy seksuele ervaring word nooit toegedig aan 'n gebrek aan respek vir vroue nie, maar aan sy viriliteit en vrees vir emosionele betrokkenheid. Wanneer die heldin sy voete onder hom uitslaan, is hy egter onmiddellik van enige promiskuiteit genees

Hy is self oneindig sexy en weet net hoe om 'n volbloedvrou te verlei en te behaag. Hy sal die heldin (of enige ander vrou in sy verlede) nooit, maar nooit teen haar sin en wil in dwing om saam met hom kooiwaarts te keer nie. Hy is teer teenoor sy heldin wanneer dit saak maak en nooit werklik gemeen teenoor enigiemand nie, hoewel hy iemand wat die heldin wil te na kom, deeglik op sy baadjie sal gee.

Hy is altyd intelligent met ' $n$ sin vir humor en het 'n sterk persoonlikheid. Vir my is die heel wonderlikste van ' $n$ held dat hy totaal cuckoo oor die heldin is - dikwels teen sy sin - en 'n intuitiewe aanvoeling vir al haar 
behoeftes het. Hy gee werklik om wanneer sy griep kry en troos haar wanneer sy huil.

Uiteindelik moet die held sy diepste gevoelens aan die heldin erken en die oomblik van emosionele binding tussen die minnaars is baie belangrik.

In 'n neutedop - stel jou die wonderlikste man op aarde voor, gee hom looks, geld en 'n mate van status, maak hom asemrowend sexy en boonop aantreklik, verbeel jou hy vrek oor jou en daar het jy die begin van jou held.

\subsection{Die heldin}

Die heldin is uit die aard van die saak die belangrikste karakter in die romanse.

"If you always write from the heroine's viewpoint, you can't go very wrong", is die eenvoudige geheim van sukses vir die gewildste Mills \& Boon-skrywer, Sheila Holland wat $£ 250000$ per jaar maak met die skryf van romanses onder die skuilnaam Charlotte Lamb.

Dit is so dat 'n heldin, soos die held, in 'n romanse tot 'n mate stereotiep is, maar binne die basiese riglyne lê daar 'n skat van moontlikhede om elkeen ' $n$ individuele identiteit te gee.

Vir my is Nina, Natalie, Saskia, Melissa, Stella en Zoë elkeen 'n ander méns, laat staan karakter. Hulle is almal aantreklik, intelligent met 'n sin vir humor en onafhanklik. Op seksuele gebied is hulle meestal naïef (al is almal nie maagde nie) en tog buitengewoon sensueel. Hulle ontdek eers hulle werklike sensualiteit sowel as seksualiteit wanneer hulle die held ontmoet, selfs al was hulle voorheen getroud of in ' $n$ intieme verhouding betrokke. Om die waarheid te sê, dink ek dat van my heldinne net Nina 'n maagd was, maar nie een was ooit promisku of self werklik "ervare" nie.

Daar is dus baie ooreenkomste tussen my heldinne, maar elkeen staan ook op haar eie bene as karakter, as mens. As ek vinnig aan hulle terugdink, is hulle elkeen vir my anders en uitsonderlik met verskillende eienskappe. Nina raak maklik verbouereerd, hoofsaaklik omdat sy sonder ma en net met 'n afgetrokke pa grootgeword het; Natalie doen dinge teen haar eie beterwete in as rebellie teen die verknogtheid van die gesin waaruit sy kom; Saskia het 'n selfbeeldprobleem omdat haar man haar altyd verkleineer het; Melissa het 'n behoefte aan sekuriteit nadat haar man doodgeskiet is in 'n motorkaping; Zoë het ' $n$ manier om haar af te sluit van mense nadat 'n vorige liefde haar veronreg het en 
Stella voel soms minderwaardig, veral ten opsigte van haar ouderdom, nadat haar man haar vir' $n$ jonger vrou gelos het.

Elkeen het dus ten minste 'n kenmerkende en onderskeidende eienskap wat gemotiveer is deur dinge wat met haar gebeur het. Soos met enige ander inligting en gebeure in ' $n$ boek is dit belangrik dat ' $n$ heldin se persoonlikheid sowel as haar handelinge deeglik gemotiveer is. Daar is niks so verspot as 'n heldin wat kastig kwaad word oor niks nie. As sy kwaad word, moet dit gemotiveer wees deur sowel haar persoonlikheid as die situasie waarin sy haar bevind.

As jou heldin nie vir jou as die skrywer volledig mens is nie, sal sy ook nie die leser oortuig nie. Jy moet weet waar sy vandaan kom, wanneer sy gebore is, hoe haar gesin gelyk en opgetree het, waar sy skoolgegaan het, onder watter sterreteken sy gebore is, met wie sy uitgegaan het, of sy ' $n$ verskuilde tattoo het of aan haar tande laat werk het, dit alles moet jy weet en nog 'n duisend ander dinge. Bitter weinig daarvan sal in jou storie te berde kom, maar die punt is dat jy haar deur en deur moet ken om haar oortuigend te kan weergee en haar oortuigend te laat optree.

Soos met my helde, het my heldinne ook foute, maar dis vergeefbare foute, foute wat hulle oorkom en waaruit hulle leer.

Ek hou dus by die basiese vereistes van die romanse-heldin, maar daarbinne diversifiseer ek soveel as moontlik sodat sy vir my werklik word.

\section{Karakters en hulle name}

Name in enige verhaal is uiters belangrik. Daar is op aarde niks verkeerd met name soos Susara of Hannatjie nie, maar dit roep net eenvoudig nie die beeld op van ' $n$ pragtige meisie met golwende blonde hare, helderblou oë en hoë wangbene nie. Daarmee sê ek nie dat die naam eksoties moet wees nie. Ek het 'n manuskrip gekeur waarin die vroulike hoofkarakter se naam Marelique was. Ek weet nie of dit die $q$ is nie, maar my oë het telkens oor die naam gestruikel. Daar is honderde name wat nie vreemd aandoen nie, maar wat steeds sogenaamde mooi name is.

Nie alleen moet name maklik lees en mooi klink nie. Versigtig vir name met konnotasies. Jy is waaghalsig wanneer jy die venynige opponent van jou heldin die naam Diana gee. Geen Diana-aanhanger sal jou dit ooit vergewe nie. Mens het ook persoonlike konnotasies wat jy aan name heg. Dit kan my byvoorbeeld nie skeel dat Nadia soet op die oor 
val en boonop ewe pragtig "hoop" beteken nie. Ek ken 'n baie oulike tiener met dié naam, maar sy is oorgewig met 'n aknee-probleem. Wanneer ek Nadia hoor, dink ek aan 'n minder gelukkige puberteitsfase en daar is geen manier waarop ek 'n heldin met daardie naam kan vereenselwig nie.

Naamboekies kan van tyd tot tyd help. In Maalstroom van ekstase het die sluwe klein Lindi haar naam aan so boekie te danke. Alhoewel die naam vir my mooi is, het ek toevallig raakgelees dat dit slang beteken en ek het geweet dat die klein onheilstoker niks anders as Lindi kon wees nie.

Sommige karakters doen hulself met naam en al aan jou voor, soos onder meer Saskia met my gedoen het. Ek het probeer redeneer dat die naam te uitheems was, maar sy het laat blyk dat sy haar op haar konstitusionele regte beroep. Dis Saskia of niks.

In Ster en komeet (werkstitel) het ek met 'n groot naamprobleem gesit. Die hoofkarakter in Komeet is 'n randkarakter in Bittersoet wals, maar 'n belangrike een. Haar naam is Leentjie. Aanvanklik het ek gedink dis maklik. Alhoewel 'n heldin moeilik met die naam Leentjie kan wegkom, is Helena of Heleen 'n pragtige suiwer naam.

Maar moenie glo nie. Ek het hierdie kant toe geskryf en daardie kant toe geskryf, maar die meetsnoere wou net nie vir my op die regte plekke val nie. ' $n$ Mens noem dit seker maar writer's block, maar ek vind die benaming nie heeltemal korrek nie. As 'n mens sukkel om te skryf beteken dit net een ding: iets is fout en jou onderbewussyn probeer jou daarop attent maak.

Ek het toe gaan sit en mooi met Heleen gepraat. Sy wou nie antwoord nie. Dit het my 'n hele ruk geneem om agter te kom waarom sy nie wil antwoord nie. Op 'n dag het die lig egter vir my opgegaan: sy luister nie, om die eenvoudige rede dat sy haarself nie as aangespreek beskou nie. Dis tóé dat die soektog na haar naam begin het. Dit moet wees hoe dit voel wanneer rekenaarhackers na 'n onbekende password soek, maar ... 'n goeie hacker seëvier op die ou einde.

Op 'n dag het het ek 'n naam uitgeroep. Dit was nie Eureka nie, maar wel Willemien. Die effek was egter dieselfde. My heldin het haar kop effens meewarig na my gedraai. "Ek het my naam afgelê in daardie ellendige konsentrasiekamp waarin jy my gedruk het. Moet my nooit weer Leentjie noem nie. Ek is Helena Wilhelmina, maar jy kan my Willemien noem". Daarna het ek en Willemien in vrede saamgeleef en kon ek haar later finaal in die arms van haar held besorg. 
Sorg dus maar dat die karakter tevrede is met die naam wat jy haar gee, maar hou jou leser ook in gedagte.

Uiteindelik is die heel belangrikste aspek van karakters egter dat hulle vir die skrywer moet leef, want as die skrywer hulle nie aan eie lyf ervaar nie, sal hulle ook nie vir die leser lewend word nie. Die skrywer moet elke karakter van binne af ervaar - nie bloot van buite sien nie.

\section{Liefdestonele}

Naas die karakters is die belangrikste element in die romanse natuurlik die liefde en daarom is die gebeure wat daar rondom plaasvind oneindig belangrik. Die geleidelike opbou van die stoom is sekerlik die heel belangrikste element in jou verhaal. Om jou held en heldin in die eerste hoofstuk in die kooi te laat beland ontlont die hele proses van afwagting wat die leser agter die blaaiende bladsye gevange hou. Daar is boeke waarin dit werk, maar ek glo die vervulling van die uitgestelde begeerte werk moeilik as die twee vanaf 'n vroeë klimaks weer van voor af moet opbou aan die spanningslyn.

Oor die "to do or not to do" van die liefdestonele wil ek ook 'n paar gedagtes opper. Dis nie nodig om eksplisiete liefdestonele in 'n romanse te hê nie. En seks hoort glad nie in 'n romanse nie. In die romanse gaan dit by uitstek oor die opbou van 'n passievolle spanningslyn, die uitgestelde begeerte, maar moet verantwoord wees en in goeie smaak. Seks sonder teerheid en sonder 'n emosionele band tussen die verliefdes is heeltemal taboe. Daarom vind ek dit so belaglik dat daar so ' $n$ bohaai oor seks in die hygroman gemaak word. As daar nou een ding is wat nie in 'n hygroman hoort nie, dan is dit seks. Die karakters in 'n hygroman/romanse word oorval deur hulle passie vir mekaar - wat natuurlik iets heeltemal anders is as seks.

So gaan Neil en Nina van Maalstroom byvoorbeeld nêrens kooi toe nie en dit word net aan die einde van die boek gesuggereer dat hulle, teen daardie tyd getroud en wel, die passie sou voltrek as die leser net so gaaf sal wees om die boek toe te maak en aan hulle bietjie privaatheid te gee. Ook in Leerskool van die liefde kom Saskia en Steph nooit by die eintlike liefdesdaad uit nie.

Jy hoef dus nie eksplisiete liefdestonele in jou romanse in te werk nie. As jy ongemaklik is daarmee, gaan die leser dit in elk geval aanvoel en self ongemaklik voel. Die leser moet in vervoering wees, nie wonder dit moreel korrek is of nie. 
Jy kies dus self die graad op die "warm"-skaal om jou persoonlikheid en jou skryfwyse te pas. As jy egter nie gemaklik voel met enige soort liefdestonele nie, is die romanse nie jou genre nie. Vry moet hulle vry, al hoef hulle nie noodwendig in die kooi te beland nie.

\section{Ten slotte}

As ek die voornemende skrywer een goeie wenk sou kon gee, sou dit die volgende wees: Onthou, die groot geheim van 'n manuskrip lê daarin dat alles in die manuskrip, of dit nou die karakters, hul handelinge, hul reaksies, hul omstandighede, liefdestonele of wat ook al is - alles moet altyd funksioneel en gemotiveer wees.

\section{Bibliografie}

Baker, Donna. 1997. Writing a Romantic Novel and Getting Published. London Hodder Headline.

Jute, A. 1994. Writing a Thriller. London: Black.

Radway, Janice A. 1994. Reading the Romance. London/New York : Verso.

Kernbegrippe:

liefdesverhaal

romanse

skryf van romanses

Key concepts:

romance

romantic novel

writing romances 
